\title{
III
}

\section{LASTRO CONSERVADOR E CAPITALISMO DEPENDENTE: UM PRESENTE RECHEADO DE PASSADO*}

\author{
Ana Cristina Oliveira de Oliveira \\ Roberta Traspadini
}

\section{Introdução $^{1}$}

O pensamento econômico ortodoxo, assentado nas premissas da economia clássica e neoclássica, mas com resquícios no próprio fundamento keynesiano, ainda que deteriorado pela crise mundial de $2008 \mathrm{em}^{\text {adiante }^{2}}$ (OLIVEIRA, 2012) e a crise sanitária de 2020 com a perda exponencial de vidas ${ }^{3}$, (CHESNAIS, 2020) não desbota nos seus artifícios ideológicos e avança exercendo força nos meios de comunicação e nos circuitos de poder. O neoliberalismo parece não conseguir prescindir de algum tipo de regulação. Isto recoloca, nos tempos modernos, o debate das correntes econômicas dentro da ordem e suas pretensas divergências reais no plano da resolução dos problemas sociais concretos. Assim, o (neo)desenvolvimentismo protege seus artefatos neoliberais, naturalizando seus feitos catastróficos no plano social e propagando-os

\footnotetext{
${ }^{*}$ DOI - 10.29388/978-65-86678-40-6-0-f.79-102

1 Algumas passagens deste artigo estão alicerçadas no desenvolvimento da tese de doutorado "Crítica à 'nova' sociabilidade do capital: por um 'capital mais humano"' (OLIVEIRA, 2012).

${ }^{2}$ Sobre a crise econômico-financeira de 2007-2009 e a recessão subsequente antes da pandemia, relacionada à sua agudização com a pandemia Covid 19. Ver CHESNAIS (2020).

3 A crise sanitária atual é caracterizada como pandemia a partir de março de 2020 pela Organização Mundial de Saúde, quando reconhece o alerta da constituição de uma Emergência de Saúde Pública de Importância Internacional pelo novo coronavírus Covid-19 (SARS-CoV-2). Disponível em: <https://www.paho.org/bra>. Acesso em: 30 jul. 2020. O Brasil, como um dos países do epicentro global do coronavírus, apresenta a alarmante marca de mais de 140 mil perdas de vidas humanas, em outubro de 2020, ampliando o leque de profundas desigualdades sociais. A respeito da crise sanitária, cf. alerta da Organização Mundial de Saúde (OMS) sobre os riscos da abertura econômica sem o controle da economia. Ver ainda: <https://www.brasildefato.com.br/2020/07/30/casos-de-covid-no-brasil-ultrapassam-2-6milhoes-onu-alerta-para-riscos-de-abertura $>$.
} 
como verdade única frente à crise mundial do capital financeiro (TRASPADINI, 2017).

As expressões dominantes das crises inerentes ao metabolismo do capital, vivenciadas no conservadorismo e recuo sistemático do processo democrático civilizatório, vão sendo impostas pelo neoliberalismo com especulações de social-liberalismo, ${ }^{4}$ presentes nos primeiros vinte anos do século XXI. Nos últimos anos, segmentos conservadores reacionários avançam sem precedentes, com novos determinantes sobrepujados na raiz religiosa-pentecostal com traços fascistas, tendo como premissa o avanço do extrativismo, a expansão da fronteira agrícola e a violação dos direitos sociais presentes na Constituição de 1988, como garantia das lutas da classe trabalhadora.

Diante deste contexto, o presente artigo tem como objetivo evidenciar o lastro ultraconservador a partir da homogeneização das ideias na sociedade de classes arraigado no Brasil contemporâneo. $\mathrm{O}$ que se propõe apresentar, através de uma revisão bibliográfica, é o favorecimento para agudização do bloco hegemônico que vem reforçando e alimentando o conservadorismo, em confronto com a Carta Constitucional de 1988 e abre precedentes para culminar na reação conservadora do último decênio legitimado pela extrema-direita no país. Para tanto, recuperaremos brevemente a história da fundação da República sob o controle da doutrina Monroe.

A reação à herança conservadora ascende, representada pela expropriação de direitos, ${ }^{5}$ pelas políticas de geração de emprego e rendimento e pelas políticas sociais estruturadas numa condição particular de modo de produção capitalista dependente, ${ }^{6}$ pela conformação do imperialismo e as enormes transferências de valores pactuadas pela relação internacional entre Norte e Sul. Este mecanismo tem impactado na formação social brasileira de forma estrutural, a partir de uma composição precarizada da força de trabalho, na reprodução do capital e na sobrevivência cotidiana dos/as trabalhadores/as e de seus familiares.

4 Como desdobramento de um conservadorismo reformista, o social-liberalismo é revelado numa postura acrítica da social-democracia contemporânea. Para maiores informações, ver Oliveira (2012).

${ }^{5}$ Para maiores informações sobre a expropriação dos direitos sociais, ver Boschetti (2017).

6“As economias dependentes inserem-se de maneira subordinada na divisão internacional do trabalho que caracteriza o mercado mundial capitalista Os determinantes estruturais dessa condição dependente são constituídos por distintos mecanismos de transferência do valor produzido nos capitalismos dependentes que são apropriados e, portanto, fazem parte do processo de acumulação das economias centrais, imperialistas" (CARCANHOLO, 2018, p. 23). 
Em tempos de contrarreforma, de retirada das promessas constitucionais e da inclusão de mecanismo de naturalização da precarização do trabalho, intensificados a partir dos anos 1990 e 2000, com o aprofundamento das relações informais de trabalho, refletem a extrema fragilidade sindical, ${ }^{7}$ (OLIVEIRA, 2020) experenciada por uma sociabilidade destrutiva nas instâncias políticas, institucionais públicas e privadas, e, não menos importante, nas ruas e demais espaços de sociabilidade.

Com a pandemia, ${ }^{8}$ os processos de expropriação social - ou seja, aquilo que Marx (1977) define como expropriação das condições necessárias para a reprodução social da vida dos trabalhadores $/$ as $^{9}$ - aprofundam-se com a privatização de bens e serviços públicos e o rebaixamento do valor da força de trabalho, constituindo mais uma transferência de recursos para o grande capital (bancos e grandes empresas), em detrimento à manutenção da superexploração da força de trabalho (AMARAL, 2012). ${ }^{10}$ O "Boletim Emprego em Pauta" do Departamento Intersindical de Estatística e Estudos Socioeconômicos (DIEESE), publicado em julho de 2020, ${ }^{11}$ revela o rebaixamento da força de trabalho sob os primeiros impactos da pandemia nas relações de trabalho. Segundo o informe, 18,5 milhões de brasileiros/as não trabalharam e não procuraram ocupação devido à pandemia; 19 milhões de pessoas foram afastadas do trabalho e $30 \mathrm{mi}$ lhões tiveram alguma redução no rendimento do trabalho. Além disso, 36\% dos

7 Sobre o debate, ver "Reforma sindical e trabalhista em debate". Cf. IHU On-Line, São Leopoldo, 25 de abril de 2005. (OLIVEIRA, 2020) Disponível em: $<$ http://www.ihuonline.unisinos.br/media/pdf/IHUOnlineEdicao138.pdf $>$. Acesso em: 20 jul. 2020 e ver: <https://www.brasildefato.com.br/2020/05/01/por-mais-lucro-neoliberaisatacam-sindicatos-para-desorganizar-trabalhadores $>$. Acesso em 23 jul. 20.

${ }^{8}$ Conforme os dados da Organização Internacional do Trabalho (OIT), no primeiro trimestre de 2020 , o resultado da retração de $4,8 \%$ na produção econômica constitui-se como o pior desde a crise de 2008 com cerca de 1,6 bilhões de trabalhadores das relações informais e 1,25 bilhão de pessoas apresentaram, na condição de empregos em setores considerados de alto risco, aumentos "drásticos e devastadores" de demissões e de reduções de salários e de horas de trabalho. Para maiores informações sobre o efeito catastrófico da pandemia de COVID-19 sobre as horas de trabalho e os ganhos globalmente. Disponível em:

$<$ https://www.ilo.org/brasilia/noticias/WCMS_741052/lang—pt/index.htm>. Acesso em: maio 2020 .

${ }^{9}$ Em certa medida, o contexto pandêmico nos alude a referenciar as condições sociais particulares do ato criativo de nós, mulheres trabalhadoras intelectuais, cuidadoras da família e de múltiplas jornadas de trabalho, entre o prazer e a dor no ato da escrita e diante das muitas mortes.

${ }^{10}$ Sobre as medidas em caráter emergencial para ajudar a mitigar os efeitos da pandemia do novo coronavírus no Brasil ver BNDES (2020) .

${ }^{11}$ Disponível em:

<https://www.dieese.org.br/boletimempregoempauta/2020/boletimEmpregoEmPauta15.pdf>. Acesso em 26 jul. 20. 
trabalhadores/as ocupados tiveram alguma perda no rendimento e a redução média salarial foi de $61 \%$.

Como tende a ocorrer em toda crise sistêmica, o preço das crises é pago pelos trabalhadores em geral, e pelos trabalhadores informais em particular. Ainda segundo o informe, os trabalhadores/as informais tiveram $56 \%$ de perda nos seus rendimentos em comparação com os $26 \%$ de perda dos trabalhadores formais, constituindo uma significativa base social disponível para o capital, servindo para rebaixar os salários e fortalecer a superexploração da força de trabalho. ${ }^{12}$

No último relatório do PNAD-COVID (Pesquisa Nacional por Amostra de Domicílios), de julho de 2020, o Instituto Brasileiro de Geografia e Estatística (IBGE) explicita que 43\% dos domicílios brasileiros receberam algum tipo de ajuda do governo relacionada a auxílio frente à condição de pandemia. ${ }^{13}$

Tais condições somente explicitam que o contexto de pandemia não gera nada novo, apenas intensifica as mazelas históricas conformadas pela relação desigual estrutural inerente à lógica da propriedade privada. Fundamento único de ser do modo de produção mercantil e sua capacidade de transformar dor em potencial mercadológico. Para isto, novamente a terra e o trabalho apresentam-se no limite da extração de valor para a perpetuação dominante da produção de riqueza mercantil. O momento atual tem sido propício para uma base política de apoio ao governo ultraconservador, com características reacionárias, ${ }^{14}$ de base assistencial ${ }^{15}$ com a iminência de mais uma contrarreforma. Em

12 A categoria superexploração da força de trabalho foi elaborada por Ruy Mauro Marini como fundamento da Teoria Marxista da Dependência (TMD). Segundo Marini (2005), no caráter sui generis do capitalismo dependente, a superexploração da força de trabalho, além de ter a intensificação e a ampliação da jornada de trabalho, também é explicitada pela remuneração abaixo do seu valor. São negadas, assim, aos trabalhadores/as, as condições necessárias para reposição do desgaste de sua força de trabalho, estimulando o esgotamento antecipado. Destacamos que há um debate contemporâneo acerca da mesma já encontrar-se nos fundamentos de Marx ou não. A nosso juízo, é um equívoco aproximá-la da concepção de ausência de desenvolvimento do capitalismo no país, ou como uma representação da depreciação do trabalho em geral no âmbito mundial. Para maiores esclarecimentos sobre a categoria superexploração, ver: Marini (2005); Luce (2012; 2018), Osorio (2009; 2013), Amaral (2012) e Traspadini (2020).

13 Para maiores informações sobre os registros da queda quantitativa de trabalhadores afastados por conta da pandemia. Disponível em:

<https://covid19.ibge.gov.br/pnad-covid/trabalho.php>. Acesso em: 27 jul. 2020.

${ }^{14}$ Sobre o negacionismo e a construção da tragédia brasileira sob a pandemia, ver: Calil (2020).

15 A base assistencial do governo Bolsonaro (2019-atual) tem sido tratada pela intencional retirada de direitos trabalhistas e sociais, agudizando as relações informais de trabalho e ampliando o controle social na forma coercitiva de um consenso intencionalmente produzido via uso da bala. Com isso, impõe uma ampliação da assistencialização (MOTA, 1995) como parte 
consequência, intensifica-se o descarado assédio sobre as terras e as culturas dos povos originários, das comunidades quilombolas; acentuam-se os assassinatos de lideranças camponesas; genocídio da juventude pobre e negra, da periferia das cidades com forte atuação do aparelho repressivo do Estado; amplia-se o discurso e a reprodução ideológica sobre a patologização das identidades trans, ampliação e qualificação do processo transexualizador com a criminalização da LGBTfobia; conforma-se uma política nacional de perpetuação do feminicídio com a flexibilização do direito à posse de armas no Brasil ampliada, entre outras reações inerentes à política conservadora reacionária. ${ }^{16}$ Uma vez mais, o imperialismo do Norte, com uma presidência além de truculenta, fascista, encontra um espelho refletor e um parceiro com ares no Sul da América.

A ideia, portanto, é evidenciar a construção de um "novo"17 consenso social projetado às classes subalternas de concepção do mundo burguês como único e irrefutável, sobre a "questão social"18 difundida como prática e ideologia pelos organismos internacionais e absorvida por parte das corporações capitalistas - as ideologias do "capital social", do (neo)desenvolvimentismo, ${ }^{19}$ do "capital mais humano" e da "ética do desenvolvimento". Este "novo" consenso coercitivo reforça o redirecionamento das esferas pública e privada na prestação de serviços sociais numa lógica contrarreformista na reconstrução de mecanismos hegemônicos mercantis.

Para darmos conta da proposta de revisão acima mencionada, o presente trabalho será dividido em três itens: 1 . Antecedentes históricos da coerção consensual no século XXI: dependência e conservadorismo na América Latina; 2. O lastro conservador espelhado na política neoliberal-(neo)desenvolvimen-

estratégica do capital de reproduzir minimamente a força de trabalho, ao mesmo tempo que aglutina um contingente de superpopulação relativa estagnada, exposta ao rebaixamento salarial.

${ }^{16} \mathrm{O}$ conservadorismo reacionário concebe um conjunto de "[...] fenômenos e movimentos de caráter político cultural (com raízes econômicas) que se intensificam na cena brasileira contemporânea, a exemplo de manifestações aproximadas a ideias integralistas, fascistas, neonazistas, xenofóbicas, racistas, entre outras, pois uma abordagem dessa natureza requisita espaço próprio" (SOUZA, 2015, p.02).

${ }^{17} \mathrm{O}$ uso recorrente do termo "nova/o" entre aspas justifica-se pela sua elevada carga ideológica e política, requerendo uma análise crítica que o desmistifique.

${ }^{18}$ Marilda Iamamoto (2004) afirma que a questão social adquire diferentes formas de acordo com o desenvolvimento das forças produtivas do modo de produção capitalista. E, também, cf. o clássico Karl Marx (1996), que explica como se manifesta a lei geral da acumulação capitalista geradora da pobreza nesta sociedade.

${ }^{19}$ Partilhamos da compreensão de que (neo)desenvolvimentismo trata-se de uma roupagem do neoliberalismo. $\mathrm{O}$ (neo)desenvolvimentismo como processo potenciado pelas políticas neoliberais que resgata o reformismo político e o conservadorismo da moralização da questão social que edificam um constructo de pensamento único. Para maiores informações, ver: Oliveira (2018). 
tista; 3. Pacote transgênico da política no século XXI: o conservadorismo como hábito social. Nas considerações finais, tentaremos apresentar algumas questões geradoras que suscitam o debate a partir das questões levantadas ao longo do texto.

\section{Antecedentes históricos da coerção consensual no século XXI}

O ano de 1964, no Brasil, marcou uma mudança concreta na relação entre Governo coercitivo e/ou Governo consensual, ainda que não haja um sem o outro. Coerção e consenso podem ser trabalhados, no âmbito da teoria política intrincada na crítica da economia política latino-americana, como movimentos cujos tons mais ou menos intensos, para cada um dos termos, dependem do teor da luta de classes no continente e no mundo a partir de determinados contextos históricos.

Mas, deve-se entender, que na trajetória histórica até a constituição do Brasil Nação, 1964 foi mais um momento, entre diversos outros, de explicitação da condição subordinada do Brasil às determinações imperialistas estadunidenses que se apresentavam desde o nascimento da República, no final do século XIX.

Em 1823, o presidente dos EUA, James Monroe, proferia em evidência propagada pela guerra o não aceite da continuidade das colônias europeias em território americano. O que não implicaria dizer-se crítico à colonização e sim adepto à sua própria forma de condicionar o continente ao jugo do poder do Norte sobre todo o hemisfério. Na aparência da aprovação das independências, a política imperialista estadunidense materializava, assim, um perverso e renovado jogo de explicitação de um território, América Latina e Caribe, para si e não para si mesma. Nas palavras de Moniz Bandeira (2008, p. 10-11):

Esta doutrina, sintetizada no lema "a América para os americanos", passara a funcionar, a partir do final do século XIX, como cobertura ideológica para o objetivo estratégico dos Estados Unidos que consistia em manter sua hegemonia sobre todo o Hemisfério Ocidental, conquistando e assegurando as fontes de matéria-prima e os mercados da América do Sul para as suas manufaturas, alijando do subcontinente a competição da Grã-Bretanha e de outras potências industriais da Europa. Daí a proposta para formar com os Estados latino-americanos 
uma comunidade comercial, uma espécie de união aduaneira, apresentada durante a Conferência Pan-Americana, instalada em Washington, em novembro de 1889.

A entrada no século XX apresentava, como antessala, uma posição política assentada na manutenção de uma ordem conservadora, latifundista, monocultora e de transição, nunca acabada, do trabalho escravo para o trabalho livre, mas não necessariamente assalariado (colonato) (MARTINS, 1983). Essa movimentação contraditória entre um aparente novo processo republicano assegurador de velhas bases coloniais, está nas bases estruturais do que se conformou, no plano hegemônico, como política nacional ao longo do século XX.

Com a defesa de uma soberania tutelada pelo Norte, então imperialista, e mantenedora dos processos violentos de invasão geopolítica dos países da América Central, os Estados Unidos forjavam, na ideia fetichizada das repúblicas, uma conformação dependente que até hoje não foi rompida. E quando houve, no bojo da luta de classes internacionais, condicionalidades postas para um movimento contrário a dita subordinação, os golpes militares dirigiam a política e o conflito existente entre o ato da rebeldia, resistência, luta pelo direito à vida e à outra ordem e a continuidade fóssil das amarras seculares de torturas sobre os povos do continente latino-americano.

Nesse sentido, resguardadas as condicionantes estruturantes de compreensão sobre a trajetória histórica de coerção e consenso na América Latina, 1964 demarca o palco contraditório de manutenção de uma herança maldita e de possibilidades de construção de uma outra história também herdeira das lutas de resistências no continente. Capitalismo dependente, imperialismo e a conformação das bases superestruturais, que gerem e são geridas pela lógica desigual, estarão presentes (MARINI, 1976).

O golpe militar de 1964 foi, assim, o resultado histórico de condições objetivas inerentes à fase de produção internacional sob a hegemonia do imperialismo estadunidense, em disputa concorrencial monopolista com o japonês e o alemão. A política coercitiva do golpe anuncia os trilhos da luta monopolista pela liderança na produção-circulação da mercadoria no âmbito mundial frente à lei tendencial da queda da taxa de lucro e os mecanismos utilizados para o avanço da concentração e centralização de capital.

De forma que, os golpes militares no âmbito do modo de produção capitalista, ontem e hoje, precisam ser compreendidos dentro da própria dinâmica de retração-expansão do capital, suas novas fases e a tendência ainda mais vio- 
lenta deste sobre os territórios e a classe trabalhadora. Os golpes, na América Latina, definem a tessitura de um duplo movimento: 1) o cercamento do continente pelos Estados Unidos frente à ameaça russa e suas respectivas particularidades revolucionárias no continente; 2) a proteção mercantil das matérias-primas e dos mercados consumidores futuros a preços exorbitantes condicionados à moeda da circulação mundial, o dólar, contra seus inimigos em cada tempo histórico na produção e valorização do capital em seu teor ampliado - no começo do século XX, Japão e Alemanha, no século XXI, China.

Segundo Marini, ao estudar a condição do golpe de Estado no Chile, que não somente depôs, mas assassinou Salvador Allende, revela a necessidade concreta da burguesia internacional e chilena de retomar as bases políticas e ideológicas que se vinculam à sua condição de preponderância "inquestionável" sobre a vida econômica do país. O golpe, coercitivo em toda sua tessitura, tentou estabelecer a ruptura com uma ordem "popular" na retomada da ordem mercantil sem freios. Nas palavras de Jaime Osório (1983, p. 78-79): "El golpe militar, que restaura la dominación burguesa sobre la sociedad, fue así el resultado del accionar político del conjunto de la burguesía, cuyas fracciones en todas sus expresiones políticas - aunque de distintas formas- actuaron con el fin de zanjar militarmente la situación". As forças armadas, na história recente dos golpes militares na América Latina, significaram mais do que a ossatura da coerção: segundo Osório, tornaram-se, acima de tudo, o cérebro da condução política a partir da moeda, da ideologia e do aparato militar estadunidense (OSÓRIO, 1983).

O que as décadas de 1960 a 1980 nos ensinam é que a coerção e o consenso, com tons diferenciados ao longo do tempo, mais abertos ou mais fechados na qualidade do vermelho (sangue, morte, tortura), dependerá da correlação de forças entre os grandes capitais imperialistas mundiais, seus Estados sedes e a forma expressiva que tomarão suas conduções nos continentes que subjugam na produção material do valor mercantil.

Nesse sentido, o conservadorismo, como armamento político societário em prol do capital, será apresentado como uma esfera natural e, como tal, formador nas células políticas das ideias dominantes de cada época. Isto é importante, porque, no plano da análise da formação ideológica de uma geração nascida nos anos de ditadura militar, veremos como resultado, na atualidade, uma concepção política cuja trajetória histórica narra o desastre da formação ideológica para a tortura, a morte, o armamento. 
O que viveremos no século XXI é a expressão mais desenvolvida do que ao longo de todo o século XX o capital forjou como sistema prisional social às ideias dominantes da época militar. Frente a isto, a luta de classes foi sendo trabalhada no ritmo do sofrimento do mundo do trabalho cada vez mais opres sor e superexplorador e de uma história de sobrevivência nas margens, pela maioria da classe trabalhadora. É desse duplo movimento - o capital e seus processos de manutenção e expansão da ordem dominante - o trabalho em sua dinâmica de resistir dentro da ordem e criar outras possíveis ordens, que se erguerá a complexidade e o retrocesso no plano dos direitos presentes no século XXI.

\section{O lastro conservador espelhado na política neoliberal- (neo)desenvolvimentista}

Com o argumento de que a capacidade humana é elemento promissor para que as habilidades econômicas sejam desenvolvidas, o Banco Mundial, a partir de 1990, passa a distinguir quatro formas de capital: capital natural compreendido o uso dos recursos naturais; capital financeiro fomentado pela sociedade expressa em infraestrutura, bens de capital; capital financeiro, imobiliário, entre outros; capital humano definido pelos graus de saúde, educação e nutrição de um povo; e o "capital social" 20 manifestado pela capacidade de uma sociedade estabelecer laços de confiança interpessoal e redes de cooperação com vistas à produção de bens coletivos (D’ARAÚJO, 2003).

Congregando os estudiosos do capitalismo dependente, defendemos a tese de que o neoliberalismo-(neo)desenvolvimentismo é uma versão atualizada das teorias do desenvolvimento com as mesmas raízes de cooperação/integração, participação social sem distinção de classes e nas versões atualizadas da ideologia do desenvolvimento em ações comunitárias (ação comunitária, ação social, organização de comunidade e desenvolvimento de comunidade) vinculadas às práticas educativas de integração num alto grau de sociabilidade e civismo. $\mathrm{O}$ que demonstra que não tem nada de novo na sua fundamentação, mas renovadas manifestações das relações sociais que contornam o conjunto de práticas de enfrentamento da "questão social". A concepção de desenvolvimento econômi-

\footnotetext{
${ }^{20}$ O capital social, de acordo com a definição do Banco Mundial, confere as "relações e normas sociais que dão qualidade às relações interpessoais em uma dada sociedade" tendo "a coesão social como um fator crítico para a prosperidade econômica e para o desenvolvimento sustentado" (D’ÁRAÚJO, 2003, p. 11).
} 
co integrado foi associada ao desenvolvimento humano e com isso apresentouse o novo fetiche acerca da suposta garantia de maiores oportunidades com uma resposta à "amenização da pobreza", sendo próprio da criação de redes pelo modelo do associativismo.

Destaca-se o discurso do capital "mais humano" com a promoção da ética como o condutor da economia pelos autores Sen e Kliksberg (2010). Parte do pensamento conservador exige abordagens alternativas à acumulação do capital sem precedentes, almejando inovar por uma perspectiva humanista capaz de "amenizar" a pobreza e reduzi-la através de um ideário reformista (exemplo típico da sociologia Durkheimiana e sua escola sociológica) do pensamento conservador como disfunção ou ameaça à coesão social na esfera da ordem estabelecida nos marcos da mundialização do capital (CHESNAIS, 1996), sob o esteio do grande capital financeiro. Objeto de uma ação moralizadora, o desenvolvimento na concentração e centralização da riqueza (MARX, 1996) tem sido um carro chefe na pedagogia da hegemonia (NEVES, 2005).

A áurea modernizadora, progressista e principalmente com um sentido humanizador de um capital -mais humanizado (SEN e KLIKSBERG, 2010; KLIKSBERG, 2003) como uma expressão dos intelectuais da hegemonia burguesa implica na ideia de, ao trabalhar o capital social, o neodesenvolvimento e a ética do desenvolvimento levaria a incorporação da dimensão humana no processo econômico. Possibilidade esta limitada pela própria essência capitalista que prioriza o capital nas relações de produção e coisifica as relações sociais na conversão das atividades e produtos humanos em mercadoria, não para satisfazer as necessidades mais elementares da população, mas para criar necessidades ampliadas de consumo (OLIVEIRA, 2012, p. 32).

Nos marcos da ideologia da sociabilidade do capital, as implicações sobre a compreensão de trabalho intermitente, trabalho voluntário, trabalho solidário, trabalho comunitário, trabalho cooperativo e associado e o trabalho alienado nos desafiam para compreender o mundo do trabalho, ainda que não para explicá-lo na sua totalidade e a correlação sobre a avanço do conservadorismo. Consideramos o universo da ideologia dominante, e sua absorção fetichizada no tempo do capital, indispensável para o estudo do desenvolvimento de políticas públicas.

Na análise de Coutinho (2011), o "pensamento conservador moderno" e "reacionário" presente nos defensores do Antigo Regime tem sua base origi- 
nária no processo de reação ao Iluminismo frente às consequências da Revolução Francesa. Há também outra modalidade que surge como oponente ao movimento revolucionário francês que se posiciona em defesa do absolutismo. Essa é a corrente do "conservadorismo liberal"(NETTO, 2011) e tem como principal representante Edmund Burke (2014).

Nos estudos de Escorsim Netto (2011) há um consenso entre os estudiosos do conservadorismo quanto à origem do seu surgimento a partir da Revolução Francesa como "[...] uma resposta reativa a tudo que a Queda da Bastilha sinalizava” (NETTO, 2011, p. 38). Em outras palavras, o conservadorismo é originário de um processo de luta de classes e da reação burguesa em defesa do Antigo Regime, com destaque à recuperação de valores do catolicismo. A função social dos pensadores conservadores que vem depois de Burke interessa aos privilegiados do Antigo Regime, a nobreza fundiária e o alto clero. Ou seja, o conservadorismo foi em sua origem uma defesa do Antigo Regime e, especialmente, do catolicismo, como uma expressão cultural da ordem burguesa. ${ }^{21}$ Entretanto, com os novos interesses de classe a partir do grau de desenvolvimento das forças produtivas, surgem novas expressões do conservadorismo para atender esses interesses de classe.

O autor, Souza (2015), ao consolidar as reflexões sobre os eixos fundamentais para entender as transformações do conservadorismo e suas expressões contemporâneas na realidade brasileira, considera que:

É possível afirmar que o conservadorismo moderno, em linhas gerais: (i) opera a desistoricização do tempo presente, baseada numa concepção de mundo "presentista"; (ii) há uma aproximação entre o sistema de ideias conservador e outras tradições de pensamento da burguesia: o liberalismo, o pragmatismo e o empirismo; (iii) o conservadorismo moderno também hiperdimensiona [...] o saber prático; (iv) faz uma dura crítica ao racionalismo e procura distância do irracionalismo, entronizando uma concepção de razão extraída das formulações positivistas; (v) valoriza a

\footnotetext{
${ }^{21}$ Neste texto, reconhecemos a diversidade de tendências do pensamento conservador clássico com os autores Joseph Maistre (1753-1821); Louis de Bonald (1754-1840); August Comte (1798-1857); Alexis- de Tocqueville (1805-1859); bem como, o pensamento conservador de Émile Durkheim (1858-1917). Porém, a ideia aqui não se conforma no estudo do pensamento conservador clássico ou mesmo o conservadorismo moderno, mas a recuperação do pensamento conservador com a preocupação de historicizá-lo como parte integrante da reação burguesa contrarrevolucionária, tendo o seu expoente ilustrador de maior penetração o Edmund Burke.
} 
função das tradições no processo de individuação; (vi) engrossa a fileira da defesa de reformas sociais que não afetem a estrutura da sociedade vigente e, nesse sentido, coloca-se como o veículo prudente para conduzir as "mudanças necessárias", sem recair nas variadas formas de "totalitarismo” (SOUZA, 2015, p. 219).

O conservadorismo contemporâneo apresenta, assim, o lastro ideológico de conformação de ideias mestras na manutenção da ordem reprodutora do capital. Capital com rosto humano, empreendedorismo, terceirização são as apostas em uma política do tipo "sossega leão" como forma de manter a alienação sob controle e domínio dos mandatários da ordem. Nesse sentido, as ideias-forças materializam a potência real de materialização de projeto do grande capital na América Latina. O conservadorismo contemporâneo, em sua feição expressiva de fascismo, conecta-se de forma indissociada com a política neoliberal-(neo)desenvolvimentista. De mãos dadas, seus mandatários delegam à classe trabalhadora a fase mais intensa de superexploração, opressão e exclusão vivenciadas no capitalismo dependente sui generis latino-americano.

\section{Pacote transgênico da política no século XXI: o conser- vadorismo como hábito social}

As formas ideológicas assumidas na atualidade, no período de "mundialização do capital" (CHESNAIS, 1996), conforme o modo de produção da vida material, condiciona o desenvolvimento da vida social, política e intelectual em geral e aposta numa uniformização das consciências consagrando uma homogeneização dos hábitos e do pensamento (MARX, 1977).

Gramsci, trazendo um elemento vivo da formação de consciência, nos diz que a concepção de mundo é "imposta mecanicamente do ambiente exterior", que, "passiva e servilmente"; torna-se "a marca da própria personalidade" (GRAMSCI, 2000, p. 93-94).

Consideramos que o modo de produção da vida material consagrado na sociedade de consumo instaura um processo de padronização ideológica na conquista da hegemonia e contribui com força por garantir um novo padrão de reestruturação produtiva. "Ciência, tecnologia e consumo são vetores importantes no processo de formação de uma sociedade globalizada" (ORTIZ, 2006, p. 32). Na direção intelectual e moral da "nova" sociabilidade, a cultura se "[...] transformou numa das principais instâncias mundiais de definição de legitimi- 
dade dos comportamentos e dos valores" (ORTIZ, 2006, p. 10). As organizações de cultura, como um dos responsáveis pela difusão ideológica, dentro do conjunto de organizações dos "aparelhos privados de hegemonia" também se apresentam como disputa de projetos societários e difusor ideológico.

Essa "nova" cultura, considerada por alguns autores como uma cultura anti-Estado, ${ }^{22}$ é produzida pela ordem burguesa internacional e assentou-se, principalmente entre os anos 1980 e 1990, na implementação de reformas neoliberais, desqualificadoras tanto do liberalismo democrático quanto das possibilidades de construção do projeto socialista (NOGUEIRA, 2001). Na conclamação da sociedade civil e das classes subalternizadas, a adesão a essa lógica desqualifica a política e a democracia.

Consideramos aqui importante mediar o debate sobre a questão do anti-Estado. A nosso ver, o capital nunca abandonou o Estado na luta hegemônica para o desenvolvimento das forças produtivas. Ao contrário da ideia de uma cultura anti-Estado, encontramos o alargamento do fundo público nos últimos anos. No fundo, o que se vê é uma cultura de anti-Estado na função social do Estado. Como um potencial ideológico poderoso, a cultura nacional impregna-se de valores, padrões, formulações e significados gerados nas nações dominantes e generalizados.

Nos dias atuais, configurada de forma mais aprimorada, o autor clássico do pensamento social brasileiro, Octavio Ianni (1976), nos chama a atenção para as questões das condições da produção, circulação e reprodução de ideias e concepções, doutrinas e teorias científicas e técnica. Diz o Ianni (1976, p. 37) sobre os principais elementos da cultura burguesa presentes nas relações, processos e estruturas de apropriação econômica e dominação política:

O capitalismo não pode funcionar, isto é, reproduzir-se continuamente se as relações sociais, econômicas, políticas ou outras não estão fundadas em princípios ou valores como os seguintes: o princípio da propriedade privada; a definição do salário como preço justo da força de trabalho; o lucro empresarial como a remuneração justa do trabalho do empresário e do seu capital; a troca de mercadorias, ou as relações de compra e venda de mercadorias como um processo independente das relações econômicas, sociais e políticas entre o operário e o capitalista; o contrato, como técnica de formalização universal das relações sociais na fábrica, na famí-

22 Para Simionatto (2004, p. 22), uma cultura anti-Estado é aquela que cimenta a necessidade de privatizar bens e serviços de natureza pública, apropriados pelas empresas privadas como fontes de novos lucros. 
lia e em todas as instituições relacionadas direta e indiretamente com a propriedade privada; a valorização da eficácia, competitividade, espírito prático, sentido de tempo, neutralidade afetiva, ascetismo, achievement, performance e outras expressões da racionalidade inerente às formas de pensar e agir características da sociedade capitalista; a identificação do capitalismo como a forma histórica superior de desenvolvimento das relações de produção (IANNI, 1976, p. 37, grifos do autor).

Ianni (1976), ao situar a peculiaridade do capitalismo dependente, afirma que as relações capitalistas de produção revelam especificidades culturais e as relações imperialistas de produção dependem tanto da produção material quanto da cultural ${ }^{23}$ para se reproduzirem. Para o autor, o capitalismo não pode funcionar, ou seja, os principais elementos da cultura burguesa não podem funcionar se não estiverem fundadas em princípios ou valores.

Partimos do pressuposto de que as estratégias para a internacionalização do capital desafiam o pensamento crítico ao buscar os nexos e denunciar as consequências da acumulação capitalista para a classe trabalhadora, argumentando que o poder do discurso da incompetência, da ausência do Estado sobre as políticas sociais, vem se tornando forte.

O capitalismo dependente, expressão de uma dependência estrutural, sob o aspecto importante das relações de tipo imperialista, "[...] revela, em detalhe, a forma pela qual o imperialismo insere-se e difunde-se no interior da sociedade subordinada; ou como se dá a interiorização das relações imperialistas, pela sociedade dependente" (IANNI, 1976, p. 122).

Florestan Fernandes (2003, p. 11, grifos do autor), convicto de que a sociedade de classe encerrou um modo de controle progressivo de certos conhecimentos básicos pelas classes trabalhadoras com a difusão de uma retórica "reformista", "nacionalista" e "desenvolvimentista", de um lado,

[...] por causa da pressão conservadora das classes dominantes, o que todos reconhecem e proclamam [...]. De outro, porque os intelectuais de classe média e abertos às "reformas de base" monopolizaram os papéis que lograram absorver, como intermediários nas estruturas do poder, e mostraram-se satisfeitos com a situação resultante.

\footnotetext{
${ }^{23}$ Para Eagleton (2005) a cultura exige certas condições sociais, e já que essas condições podem envolver o Estado, pode ser que ela também tenha uma dimensão política e social. Nenhum poder político pode se manter satisfatoriamente por meio de pura e simples coerção.
} 
A natureza da burguesia nacional é carregada da base oligárquica que se faz dentro de um horizonte cultural que essencialmente era o mesmo. Portanto, temos uma burguesia que se vincula a uma prática autocrática, herdada do passado ou improvisada no presente. (idem).

[...] uma burguesia que teve uma de suas raízes no nexo estrutural entre a escravidão e a acumulação primitiva de capital, que tem de recorrer ainda hoje a certas modalidades pré-capitalistas de acumulação e que não rompeu (e nunca tentou decisivamente romper), com os laços visíveis e invisíveis da dominação indireta (por via do mercado mundial ou, mais tarde, da internacionalização das formas de produção) não produz socialmente, dentro e através de suas situações de classe, o impulso coletivo para as grandes reformas (ou revoluções encadeadas) que colocam o desenvolvimento do capitalismo no clímax da história das civilizações. Mesmo que esse impulso se configurasse, psicológica, cultural e socialmente, ela não contaria com base material suficiente para convertê-la em realidade (FERNANDES, 1982, p. 108, grifos do autor).

Uma consolidação conservadora da dominação burguesa no Brasil, assim denominada por Florestan Fernandes. A reprodução do ethos burguês entre coerção e consenso é nada mais que o padrão de civilização coadunado com a expansão mundial do capitalismo. O que torna essencial a constituição de uma formação social subsequente por atitudes e comportamentos de um novo tipo antecedentes à consolidação de uma economia de mercado de bases capitalistas - os "modos de ser, pensar e agir socialmente" (FERNANDES, 2008, p. 39).

Considerando os elementos analisados por Marini $(2005,2010)$ sobre a dialética da dependência com base no método marxista, o capitalismo dependente não se constitui numa relação de subordinação política entre nações capitalistas. Pressupõe que a dependência é uma particularidade do capitalismo e, neste sentido, compreende três elementos relacionados à mesma: i) pela transferência de valor para as economias centrais; ii) pela superexploração da força de trabalho; e iii) pela agudização das contradições inerentes ao ciclo do capital, considerando a produção de mercadorias destinadas para a exportação e para as elites.

Portanto, elucidar o pensamento conservador revestido de progressista, ou ainda, na conjuntura atual de retomada de um conservadorismo clássico (NETTO, 2011), é um elemento crucial porque este caldo (neo)conservador vem reatualizando no pensamento social concepções presentes nas vertentes 
(neo)conservadoras de forte presença do pensamento pós-moderno que tem um discurso legitimador de natureza cultural fundado na estrutura econômica. Desde os anos 2000 o caldo conservador vem sendo reatualizado e estes influxos já começam a serem sentidos e, no nosso entendimento, na atualidade, encontram-se cada vez mais atualizados.

O capital se reveste com uma "nova" 24 roupagem se apresentando como "capital social" e "mais humanizado" (OLIVEIRA, 2012). Esta roupagem remete ao significado de uma relação direta com a ideia de desenvolvimento (sustentável) para uma democracia associada a um possível capital "mais humano" (OLIVEIRA, 2012).

A disseminação desse pensamento no enfrentamento à pobreza ascende na guinada do milênio (a partir de 2000) sendo difundida como prática e ideologia pelos organismos internacionais ${ }^{25}$ e absorvida por parte das corporações da sociedade civil.

Nesta direção, a visão do pensamento "único" remete à ideia de "novo" caracterizado como uma alternativa ao neoliberalismo com o objetivo de superar a crise que se constituiu a partir das reformas preconizadas pelo Fundo de Monetarização Internacional (FMI). Remete à ênfase que alguns autores contemporâneos situam a atual sociabilidade burguesa para que os Países em Desenvolvimento, num recorte latino-americano, se tornem compatíveis com o contexto de mudanças internacionais e nacionais do capital de juros nos planos tecnológico, político e econômico, defendido pela "nova" CEPAL (Comissão Econômica para a América Latina e Caribe) e Banco Mundial.

No contexto da pobreza e desigualdade social, a política neoliberal(neo)desenvolvimentista conta com intelectuais da "nova" pedagogia da hegemonia (NEVES, 2005) com um discurso carregado de alternativa ao neoliberalismo. Este ideário para atingir este legado de mudanças culturais que evitam o conflito educa para a tolerância, paz e confiança mútua.

Neste cenário, o Estado tem papel fundamental na condução desta função política de construção de um mercado forte. Uma promoção de um am-

\footnotetext{
${ }^{24}$ A palavra "nova" aparece aqui entre aspas significando que a "nova" roupagem não é nova porque reafirma os interesses do capital. Isto é, a acumulação de riquezas sob a exploração do trabalho, entendendo a incompatibilidade entre o capital e um capital "mais humano" na sociabilidade burguesa.

25 A política neoliberal-(neo)desenvolvimentista, que aparece como uma alternativa ao neoliberalismo, encontra-se coadunada com os organismos internacionais, entre outros o Banco Mundial; Comissão Econômica para a América Latina e o Caribe (CEPAL) e Fundo Monetário Internacional (FMI) (OLIVEIRA, 2012).
} 
biente de cooperação entre Estado-mercado-sociedade civil, construindo uma 'cultura cívica' arrolada em valores de solidariedade e cooperação para construir o bem-estar social (OLIVEIRA, 2012). Seja pelo braço do capital mais humanizado com base no solidarismo, ajuda mútua, associativismo, "cultura cívica", ${ }^{26}$ ou ainda, pelas incursões do pensamento conservador moderno.

\section{Considerações finais}

Este texto partiu de uma consideração concreta: a história do conservadorismo na América Latina desde a constituição da República até o momento contemporâneo, tendo como premissa os tons da coerção e do consenso efetivados pelos Estados Unidos como país imperialista conformador da lógica da dependência nos séculos XX e XXI. Nesse sentido, tanto os conflitos ao longo do século XIX de consolidação tutelada das independências na América Latina, como os processos de industrialização ao longo do século XX, narram a faceta do capitalismo dependente como a faceta mais dura das amarras do imperialismo sobre o continente.

Esta condicionante de dependência que tem como substância a superexploração da força de trabalho, a expansão do latifúndio e o controle das burguesias sobre a condução econômico-político-ideológica, nos faz estabelecer uma relação direta entre o passado e presente da história de lutas no nosso continente.

Diante isto, algumas perguntas se fazem necessárias como forma de mantermos aberto o debate proposto neste trabalho: 1) A conformação dos Estados Nacionais na América Latina abriu alas a que tipo de consolidação nacionalista e democrática?; 2) O conservadorismo no século XXI narra que novas condicionalidades frente às velhas produções materiais de coerção e consenso?; 3) As gerações nascidas sob a ditadura conformam, em pleno século XXI, que direcionamento político sobre a vida, portanto, foram educadas para que sentido de pátria, de ordem e de progresso?; 4) As revoluções na América

\footnotetext{
${ }^{26}$ A palavra "nova" aparece aqui entre aspas significando que a "nova" roupagem não é nova porque reafirma os interesses do capital. Isto é, a acumulação de riquezas sob a exploração do trabalho, entendendo a incompatibilidade entre o capital e um capital "mais humano" na sociabilidade burguesa. A política neoliberal-(neo)desenvolvimentista, que aparece como uma alternativa ao neoliberalismo, encontra-se coadunada com os organismos internacionais, entre outros o Banco Mundial; Comissão Econômica para a América Latina e o Caribe (CEPAL) e Fundo Monetário Internacional (FMI) (OLIVEIRA, 2012).
} 
Latina, ao eclodirem ao longo de todo o século XX, apresentam que contrapeso à história do conservadorismo no continente? Estas questões abrem horizontes reflexivos para novos trabalhos a partir das bases materiais concretas que conformam uma sociedade que, ao naturalizar a precarização, a superexploração e a opressão, define como horizonte de sentido possível a banalização da vida.

O que elucidamos, ao trazer estes elementos, é a renovação do conservadorismo na contemporaneidade na realidade brasileira com a retomada do pensamento ortodoxo, liberal, no curso da reprodução ampliada do capital. Está na ordem do dia, no âmbito do pensamento social, o desprezo pela dimensão ontológica do real.

O conjunto de materialidade do pensamento conservador evoca compreender as contrarreformas do Estado, a conformação de uma política alienadora sobre a sociedade civil e sua materialização do rebaixamento das políticas públicas, como natureza específica da sociedade de classe contemporânea sob o domínio do capital.

A aposta na ausência de identidade de classe, na criminalização das ideias progressistas e na produção violenta de uma política "fake news", conformam, hoje, na América Latina e, em especial no Brasil, o fetichismo das políticas oriundas dos organismos internacionais como Fundo Monetário Internacional e Banco Mundial. Ancorados na ideia de uma maior equidade e redistribuição de renda nas direções de solidarismo, "ajuda mútua" e associativismo, cultura cívica, rede social, paz, segurança e cooperação, estes organismos incidem em mecanismos de função de direção intelectual e moralista que conduzem a um processo de "educação para o conformismo" (MOTA, 2007).

Nesta seara, o solidarismo, a "cultura da paz", o comunitarismo, a rede social, etc., escamoteiam a produção e reprodução das relações sociais ao confundirem-se como uma perspectiva progressista, na inauguração de uma transformação anticapitalista. Consideramos que estão fundamentadas, de fato, nas forças reformistas e contrarrevolucionárias na América Latina, distanciando-se da proposta da Constituição Federal de 1988 e de consolidação dos direitos sociais e, neste contexto, despolitizando as políticas sociais. Trata-se de incentivar a sociedade civil na direção ética e política para a construção de uma cultura burguesa hegemônica.

Neste sentido, concluímos que o conservadorismo, ao avançar no tom reformista do neoliberalismo-(neo)desenvolvimentista, base de sua essência clássica, sob a égide do social liberalismo como uma ideologia de manutenção da ordem capitalista, cria respaldo para um certo tipo de "limpeza" da esquerda. 
Os intelectuais da pedagogia da hegemonia (NEVES, 2005), numa batalha de ideias, sustentam um mecanismo de conservação de uma unidade ideológica introduzindo, no discurso, a ideia de "novo", que de novo não tem nada, dada suas ações que não problematizam as bases da acumulação capitalista, produtora de riqueza e inversamente da miséria ao mesmo tempo. Nestes termos, tratamos de chamar a atenção no legado da constituição do que o bloco hegemônico constitui como "novo", para garantir o consenso e a legitimidade do neoliberalismo-neodesenvolvimentismo pelo uso dos aparelhos coercitivos de dominação. Os argumentos, por hora traçados aqui, culminam mais numa aproximação sinalizando os apostes singulares de explicitação da homogeneização dos hábitos e do pensamento conservador.

Após a vigência do período progressista na América Latina, e das contradições que o mesmo apresenta, dada a manutenção da ordem burguesa acerca da política de desenvolvimento, a profusão conservadora das políticas neoliberais-(neo)desenvolvimentistas apresenta-se novamente em cena, porém de forma mais agressiva, reacionária, consolidando-se como um consenso para parte da população na ideia de "limpeza" da esquerda no continente.

Nesse sentido, a dependência ganha ainda mais força frente ao avanço do imperialismo e o mundo do trabalho, tão desigual, vê-se ainda mais agredido nos mínimos direitos conquistados ao longo dos séculos XX e XXI. No horizonte do processo democrático civilizatório, precisamos revigorar a resistência nos movimentos articulados de massa no apoio com a educação popular identificando os novos determinantes da homogeneização do pensamento conservador.

\section{Referências}

AMARAL, M. S. Teorias do imperialismo e da dependência: a atualização necessária ante a atualização do capitalismo. 2012.147f. Tese (Doutorado em Ciências). Departamento de Economia. Programa de Pós-Graduação em Economia, Universidade de São Paulo, São Paulo, 2012. Disponível em: < https://teses.usp.br/teses/disponiveis/12/12140/tde-09102012-174024/publico/MarisaSilvaAmaralVC.pdf >. Acesso em: 15 jul. 2020.

BANDEIRA, L. A. M. A Importância Geopolítica da América do Sul na Estratégia dos Estados Unidos. Revista da Escola Superior de Guerra, Rio de Ja- 
neiro, v. 24, n. 50, p. 7-35, jul./dez. 2008. Disponível em: < https://revista.esg.br/index.php/revistadaesg/article/view/272/242 >. Acesso em: 20 jul. 2020. BNDES. BNDES lança primeiras medidas para reforçar caixa de empresas e apoiar trabalhadores que enfrentam efeitos do coronavírus. Banco Nacional de Desenvolvimento Econômico e Social. MPMEs | Institucional | Coronavírus - Ações emergenciais, 22 de março de 2020. Disponível em: < https://www.bndes.gov.br/wps/portal/site/home/imprensa/noticias/conteudo/bndes-lanca-primeiras-medidas-para-reforcar-caixa-de-empresas-eapoiar-trabalhadores-que-enfrentam-efeitos-do-coronavirus $>$. Acesso em: 17 ago. 2020.

BOSCHETTI, I. Agudização da barbárie e desafios ao Serviço Social. Serv. Soc. Soc., São Paulo, n. 128, p. 54-71, jan./abr. 2017. Disponível em: < http://www.scielo.br/scielo.php?script=sci_arttext\&pid=S010166282017000100054\&lng=en\&nrm=iso >. Acesso em: 20 fev. 2018. doi: http://dx.doi.org/10.1590/0101-6628.093.

BURKE, E. Reflexões sobre a revolução na França. Tradução José Miguel Nanni Soares. São Paulo: EDIPRO, 2014.

CALIL, G. Negacionismo e guerra de informações na construção da tragédia brasileira sob a pandemia. In: Marx e Marxismo, Niterói, v. 8, n. 14, p. 177187, jan/jun 2020.

CARCANHOLO, M. A crise do capitalismo dependente brasileiro. In: MACÁRIO, E. et al. Dimensões da crise brasileira: dependência, trabalho e fundo público. 1. ed. Fortaleza: EdUECE; Bauru: Canal 6, 2018. p. 23-55.

CHESNAIS, F. A mundialização do capital. São Paulo: Xamã, 1996. . Capitalismo está diante de uma parede, diz chesnais. Tutaméia. Entreveros e Desenredos. Entrevistas em destaque por Eleonora de Lucena e Rodolfo Lucena. 1 de maio de 2020. Disponível em: <https://tutameia.jor.br/capitalismo-esta-diante-de-uma-parede-diz-chesnais/ > . Acesso em: 06 jun. 2020.

COUTINHO, C. N. Prefácio. In: NETTO, L. E. O conservadorismo clássico: elementos de caracterização e crítica. São Paulo: Cortez, 2011. p. 9-11.

D'ARAUJO, M. C. Capital Social. Coleção Passo a Passo, v. 25. Rio de Janeiro/RJ: Zahar, 2003.

DIEESE. Boletim Emprego em Pauta. Departamento Intersindical de Estatística e Estudos Socioeconômicos, jul. 2020. 
EAGLETON, T. A Ideia da Cultura. Tradução Sandra C. Cranco. Revisão técnica Cezar Mortari. São Paulo: UNESP, 2005.

NETTO, L. E. O conservadorismo clássico: elementos de caracterização e crítica. São Paulo: Cortez, 2011.

FERNANDES, F. A ditadura em questão. São Paulo: T. A. Queiroz, 1982. . Prefácio. In: AMMANN, S. B. Ideologia do Desenvolvimento de Comunidade no Brasil. 10. ed. São Paulo: Cortez, 2003. . Sociedade de classes e subdesenvolvimento. São Paulo: Global, 2008.

GRAMSCI, A. Maquiavel, notas sobre o Estado e a política. In: Caderno do Cárcere. v. 3. Rio de Janeiro: Civilização Brasileira, 2000.

IAMAMOTO, M. A Questão Social no Capitalismo. Temporalis, Brasília, ano 2, n. 3, 2004. p. 9-32.

IANNI, O. Imperialismo e cultura. Petrópolis: Vozes, 1976.

IBGE. Pesquisa Nacional de Amostragem por Domicílio - PNAD (contínua). IBGE, Rio de Janeiro, 23 jul. 2020.

LUCE, M. S. A superexploração da força de trabalho no Brasil. Revista Soc. Bras. Economia Política, São Paulo, v. 1, n. 32, p. 119-141, jun. 2012.

Teoria Marxista da Dependência. Problemas e categorias - Uma visão histórica. São Paulo: Expressão Popular, 2018.

MARINI, R. M. Dialética da Dependência. In: TRASPADINI, R.; STÉDILE, J. P. (Orgs). Ruy Mauro Marini, vida e obra. São Paulo: Expressão popular, 2005, p. 137-180.

. A crise do desenvolvimento. In: CASTELO, R. (org.). Encruzilhadas da América Latina no século XXI. Rio de Janeiro: Pão e Rosas, 2010, p. 103-118.

. El reformismo y la contrarrevolución. Estudios sobre Chile.

México: Serie Popular Editora Era, 1976.

MARTINS, J. de S. Os camponeses e a política no Brasil. São Paulo: Editora Vozes, 1983.

MARX, K. Contribuição à crítica à economia política. São Paulo: Martins Fontes, 1977.

. O Capital, liv. marxI, t. 2. Col. Os Economistas. São Paulo: Nova Cultural. 1996. 
MOTA, A. E. Cultura da crise e seguridade social: um estudo sobre astendências da previdência e da assistência social brasileira nos anos 80 e 90. São Paulo: Cortez, 1995.

\section{MOTTA, V. C. Da Ideologia do Capital Humano à Ideologia do Capital}

Social: as políticas de desenvolvimento do milênio e os novos mecanismos hegemônicos de educar para o conformismo. 2007. 379 f. Tese (Doutorado em Serviço Social) - Programa de Pós-graduação em Serviço Social, Universidade Federal do Rio de Janeiro, Rio de Janeiro, 2007.

NEVES, L. M. W. A nova pedagogia da hegemonia: estratégias da burguesia brasileira para educar o consenso na atualidade. São Paulo: Xamã, 2005.

NOGUEIRA, M. A. Em defesa da política. São Paulo: Editora Senac, 2001. ORTIZ, R. Mundialização e Cultura. Brasiliense: São Paulo, 2006. OLIVEIRA, A. C. O. de. Crítica à nova sociabilidade do capital: por um “capital mais humano". 2012. 611 f. Tese (Doutorado em Serviço Social) Programa de Pós-Graduação em Serviço Social da Faculdade de Serviço Social, Universidade do Estado do Rio de Janeiro, Rio de Janeiro, 2012. . Conservadorismo, Banco Mundial e Serviço Social: o (neo) desenvolvimentismo e as reformas sociais. Temporalis, Brasília, ano 18, n. 35, p. 244 264, jan./jun. 2018.

OLIVEIRA, C. Por mais lucro, neoliberais atacam sindicatos para desorganizar trabalhadores. Transformações no mundo do trabalho impõem desafio de manter trabalhadores organizados e defender direitos históricos. Brasil de Fato, São Paulo, 01 de Maio de 2020, Disponível em: <https://www.brasildefato.com.br/2020/05/01/por-mais-lucro-neoliberais-atacam-sindicatos-para-desorganizar-trabalhadores $>$. Acesso em: 17 ago. 2020.

OIT. OIT: COVID-19 causa perdas devastadoras de empregos e horas de trabalho. Organização Internacional do Trabalho. Notícias, Brasília, 07 abr. 2020. OSÓRIO, J. Chile: Estado y dominación. Cuadernos Políticos, Chile, n. 36, ediciones era, p. 73-86, abril/jun. 1983. Disponível em: < http://www.cuadernospoliticos.unam.mx/cuadernos/contenido/CP.36/CP.36.8.JaimeOsorio.pdf>. Acesso em: 18 jul. 2020.

. Dependência e superexploração. In: MARTINS, C. E.; VALENCIA, A. S. (Orgs.). A América Latina e os desafios da globalização. Ensaios dedicados a Ruy Mauro Marini. São Paulo: Boitempo, 2009. 
. Fundamentos da superexploração. In: FILHO, N. A. (Org.). Desenvolvimento e dependência. Brasília: Instituto de Pesquisa Econômica Aplicada, 2013.

SEN, A.; KLIKSBERG, B. As pessoas em primeiro lugar: a ética do desenvolvimento e os problemas do mundo globalizado. Tradução Bernardo Ajzemberg, Carlos Eduardo Lins da Silva. São Paulo: Companhia das Letras, 2010.

SIMONATTO, I. Estado e sociedade civil em tempos de globalização: reinvenção da política ou despolitização? Revista Katálysis, Florianópolis, v. 7, n. 1, 2004, p.19-30.

SOUZA, J. M. A. de. O Conservadorismo Moderno: esboço para uma aproximação. Revista Serviço Social \& Sociedade, n. 122, abril/jun. 2015. Disponível em: <http://www.scielo.br/pdf/sssoc/n122/0101-6628-sssoc-1220199.pdf>. Acesso em: 18 jul. 2020.

TRASPADINI, R. Breve genealogía del capitalismo dependiente latinoamericano: la superexplotación como combustible del neodesarrollismo. In: FÉLIZ, M.; PINASSI, M, comp. La farsa neodesarrollista y las alternativas populares en América Latina y el Caribe. Buenos Aires: Herramienta, 2017. En Memoria Académica. Disponible en: < http://www.memoria.fahce.unlp.edu.ar/libros/pm.561/pm.561.pdf>. Acesso em: 18 jul. 2020.

. Dependência, superexploração e neoconservadorismo na América Latina. Venenos presentes de um passado vivo. Le monde Diplomatique. Acervo Online Brasil. São Paulo, 15 março 2020. Disponível em: < https://diplomatique.org.br/dependencia-superexploracao-e-neoconservadorismo-naamerica-latina/>. Acesso em: 20 jul. 2020. 